\title{
The Preproghrelin 3056 TT Genotype is Associated with the Feeling of Hunger and Low Acylated Ghrelin Levels in Japanese Patients with Helicobacter pylori-negative Functional Dyspepsia
}

\author{
Seiji Futagami ${ }^{1}$, Mayumi Shimpuku ${ }^{1}$, Tetsuro Kawagoe ${ }^{1}$, Nikki Izumi ${ }^{1}$, Noriko Ohishi ${ }^{1}$, \\ Hiroshi Yamawaki ${ }^{1}$, Tomotaka Shindo ${ }^{1}$, Hiroyuki Nagoya ${ }^{1}$, Akane Horie ${ }^{1}$, Yasuhiro Kodaka ${ }^{1}$, \\ Katya Gudis ${ }^{1}$, Takashi Itoh ${ }^{2}$ and Choitsu Sakamoto ${ }^{1}$
}

\begin{abstract}
Objective An impairment of gastric motility is strongly associated with the pathophysiology of functional dyspepsia (FD). Plasma ghrelin is one of the key molecules linked to gastric motility. Therefore, this study aimed to evaluate whether ghrelin (GHRL) gene polymorphisms are associated with clinical symptoms, the plasma ghrelin levels and gastric emptying in patients with FD as defined by the Rome III classification.

Methods We enrolled 74 Helicobacter pylori-negative patients presenting with typical symptoms of FD (epigastric pain syndrome (EPS), $n=23$; postprandial distress syndrome (PDS), $n=51$ ) and 102 healthy volunteers. Gastric motility was evaluated according to the Tmax value and $\mathrm{T}_{1 / 2}$ using the ${ }^{13} \mathrm{C}$-acetate breath test. We used the Rome III criteria to evaluate upper abdominal symptoms and SRQ-D scores to determine the depression status. The Arg51Gln(346G->A), preproghrelin3056T- $>$ C, Leu72Met(408C->A) and Gln90Leu (3412T->A) polymorphisms were analyzed in DNA in blood samples obtained from the enrolled subjects. Genotyping was performed using polymerase chain reaction.

Results There was a significant relationship $(\mathrm{p}=0.048)$ between the preproghrelin 3056TT genotype and the serum levels of acylated ghrelin in the $H$. pylori-negative FD patients. The preproghrelin 3056TT genotype was significantly $(\mathrm{p}=0.047)$ associated with the feeling of hunger in the $H$. pylori-negative FD patients.

Conclusion The preproghrelin 3056TT genotype is significantly associated with the acylated ghrelin levels and the feeling of hunger in $\mathrm{H}$. pylori-negative FD patients. Further studies are needed to clarify the association between the preproghrelin 3056TT genotype and lower plasma acylated ghrelin levels and the impact of this relationship on the feeling of hunger in H. pylori-negative FD patients.
\end{abstract}

Key words: functional dyspepsia, gastric motility, polymorphism, preproghrelin, the feeling of hunger, acylated ghrelin

(Intern Med 52: 1155-1163, 2013)

(DOI: 10.2169/internalmedicine.52.8662)

\section{Introduction}

Functional dyspepsia (FD) is a common gastrointestinal disorder that has been subclassified into two new disease categories under the Rome III classification: epigastric pain syndrome (EPS) and postprandial distress syndrome (PDS) (1). Impairment of gastric motility, including gastric emptying, is strongly associated with the pathophysiology of FD (2). Impaired physiological gastric emptying in patients with FD is accompanied by a variety of symptoms ranging from premature saturation, fullness, nausea, vomiting, epi-

${ }^{1}$ Department of Internal Medicine, Division of Gastroenterology, Nippon Medical School, Japan and ${ }^{2}$ Center for Information Sciences, Nippon Medical School, Japan

Received for publication July 23, 2012; Accepted for publication February 7, 2013

Correspondence to Dr. Seiji Futagami, seiji.futagami@gmail.com 
gastric pain and acid reflux accompanied by delayed emptying. We have previously reported that the Tmax value, a marker of gastric emptying, is significantly greater in PDS patients compared to that observed in healthy volunteers (3). In addition, we have also reported that low levels of serum acylated ghrelin are significantly associated with disturbed Tmax values (3).

Ghrelin (GHRL) is predominantly produced in the stomach, and substantially lower amounts are derived from the bowel, pancreas, pituitary, kidneys and placenta. GHRL is recognized to be an endogenous ligand for the growth hormone secretagogue receptor in the oxyntic gland of the stomach (4). The plasma ghrelin concentration rises during fasting and falls quickly after meals (5). Therefore, GHRL plays a role in the long-term as well as short-term regulation of feeding (6). In human studies, the administration of GHRL increases food intake and the sensation of hunger compared with saline infusion alone (7). In rodents, central or peripheral administration of GHRL stimulates gastric contraction and emptying (2) and exhibits prokinetic effects in a postoperative ileus model in rats (8). In pharmacologic studies, acylated ghrelin has been shown to accelerate gastric emptying, increase gastric tone and induce premature interdigestive migrating motor complex activity.

The preproghrelin gene codes for two short hormones, ghrelin and obestatin. The gene encoding preproghrelin, the ghrelin precursor, is located on chromosome 3(3p25-26) and comprises four exons and three introns (9). Three nonsynonymous single nucleotide polymorphisms (SNPs) in the GHRL gene have been reported. The Arg 51Gln SNP is associated with lower GHRL and insulin-like growth factor I concentrations (10). The Leu72Met SNP has been linked to obesity-related phenotypes; however, these findings are controversial (9-11).

In this study, we aimed to investigate whether GHRL gene SNPs contribute to FD symptoms by impairing gastric emptying and reducing the acylated ghrelin levels in Helicobacter pylori (H. pylori)-negative Rome III-based FD patients.

\section{Materials and Methods}

\section{Patients}

Seventy-four $H$. pylori-negative patients presenting with typical symptoms of FD (EPS, n=23; PDS, n=51) and 102 healthy volunteers were enrolled after undergoing upper gastrointestinal endoscopy and abdominal ultrasonography. The patients were diagnosed according to the Rome III criteria (12). The healthy volunteers were recruited from among the Japanese medical staff of Nippon Medical School who had no clinical history of gastroduodenal disease, including clinical symptoms of FD. Three of the healthy volunteers were $H$. pylori-positive. The exclusion criteria included severe heart disease, renal or pulmonary failure, liver cirrhosis, severe systemic illness and a history of malignant disease.
Patients with a history of previous gastroduodenal surgery, duodenal ulcer scars, diabetes mellitus and recent use of nonsteroidal anti-inflammatory drugs (NSAIDs), proton pump inhibitor (PPIs) or anticoagulants at endoscopy were also excluded. The presence of $H$. pylori infection was determined using both the ${ }^{13} \mathrm{C}$-urea breath test and histological identification. Written informed consent was obtained from all subjects prior to undergoing upper gastrointestinal endoscopy and abdominal ultrasonography for an evaluation of their dyspeptic symptoms. The study protocol was approved by the Ethics Review Committee of Nippon Medical School Hospital.

\section{Clinical symptoms}

The clinical symptoms of FD were evaluated according to the Rome III criteria (12). The clinical symptoms must have involved at least one of the following: early satiation, bothersome postprandial fullness, epigastric pain or epigastric burning. The diagnostic criteria for PDS included bothersome postprandial fullness occurring after ordinary-sized meals and/or early satiation that prevented completion of a normal meal, with either symptom occurring at least several times a week. The diagnosis of EPS was made based on all of the following: pain or burning that is intermittent, localized to the epigastrium and of at least moderate severity occurring at least once per week. A diagnosis of PDS and EPS was fulfilled based on symptoms occurring for the last three months and the onset of symptoms occurring at least six months prior to diagnosis. In this study, we enrolled PDS patients without abdominal pain or epigastric burning. One patient diagnosed with EPS experienced symptoms that overlapped those of PDS. Abdominal symptoms, including the feeling of hunger, were assessed using a modified questionnaire that has been applied in previous studies and the feeling of hunger was evaluated according to three factors, including frequency, intensity and duration as follows: none, 5; one-two days/3 months, 4; one day/month, 3; one day/ week, 2; half a day, 1; all day, $0(1,13,14)$. We assessed abdominal symptoms using the modified Glasgow dyspepsia severity score (15), which evaluates the frequency of dyspeptic symptoms over the past six months (never, score 0; on only 1 or 2 days, score 1 ; on approximately 1 day per week, score 3; on approximately $50 \%$ of days, score 4 ; and on most days, score 5), the duration of symptoms (maximal score 5) and the intensity of symptoms (maximal score 3). The status of depression was evaluated using the SRQ-D (Self-Rating Questionnaire for Depression) score (16). The health-related quality of life (HR-QOL) was assessed using the Japanese version of the 8-item Short-Form Health Survey (SF-8) (17). Scores for the eight domains ("general health," "physical functioning," "role-physical," "bodily pain," "vitality," "social functioning," "mental health" and "role-emotional") and two summaries (physical component summary (PCS) and mental component summary (MCS)) were derived. A score $<50$ indicates an impaired QOL. 


\section{Measurement of gastric motility}

Sodium acetate (water soluble) was used as a tracer to evaluate emptying of liquids (Cambridge Isotope Laboratories; MA, USA). The probes were analyzed using nondispersive infrared spectroscopy (IRIS, Wagner Analyzentechnik; Bremen, Germany). The subject's own production of 300 mmol $\mathrm{CO}_{2}$ per $\mathrm{m}^{2}$ body surface and per hour were set as the default. We used an Integrated Software Solutions program to calculate the half gastric emptying time $\left(\mathrm{T}_{1 / 2}\right)$ and the lag phase (Tmax; min) as the point of maximum gastric emptying according to Hellmig et al. (18). The half gastric emptying time $\left(\mathrm{T}_{1 / 2}\right)$ represents the time when $50 \%$ of the initial gastric content is emptied. A Tmax value greater than 60 minutes, representing the mean Tmax plus SD in healthy volunteers, was defined as indicating relative disturbances in gastric emptying according to the diagnostic criteria of the Japan Society of Smooth Muscle Research and our study $(3,19)$.

\section{Study protocol for gastric emptying of liquids}

We used a liquid test meal consisting of $100 \mathrm{mg}$ of ${ }^{13} \mathrm{C}$ acetate dissolved in $200 \mathrm{~mL}$ of liquid meal (Racol, $1 \mathrm{~mL} / \mathrm{L}$ kcal; Otsuka Pharmacia Company, Tokyo, Japan). Breath samples were collected at $0 \mathrm{sec}, 10 \mathrm{sec}, 5 \mathrm{~min}, 10 \mathrm{~min}, 15$ $\mathrm{min}, 20 \mathrm{~min}, 30 \mathrm{~min}, 40 \mathrm{~min}, 50 \mathrm{~min}, 60 \mathrm{~min}, 75 \mathrm{~min}$ and $90 \mathrm{~min}$ after ingestion of a test meal at 10:00 a.m. Patients were instructed not to drink, eat or smoke during the test.

\section{Genotyping}

We developed or optimized the following assays for genetic variation. Genotypes were confirmed or selectively assessed for GHRL (Arg51Gln 346G->A; rs:34911341), (preproghrelin 3056T- $>$ C; rs:2075356), (Leu72Met 408C- $>$ A; rs: 696217) and (Gln90Leu 3412T->A; rs:4684677) genotypes using direct sequencing with the ABI 7500 Fast. Gene polymorphisms were determined according to methods reported in other studies. Real-time polymerase chain reaction using TaqMan chemistries (Applied Biosystems, Foster City, CA) was used to identify the alleles present in each sample. Real-time polymerase chain reactions were performed in an Applied Biosystems 7500 Fast machine (Applied Biosystems). Taq Man primer-probe assays for Arg51Gln SNPs 346G->A (rs:34911341; C-25607739-20), preproghrelin SNPs 3056T->C (rs:2075356; C-3229939-1), Leu72Met SNPs 408C->A (rs: 696217; C-3151003-20) and Gln90Leu SNPs 3412T->A (rs: 4684677; C-25607748-10) were purchased from Applied Biosystems. Briefly, each reaction volume was $10 \mu \mathrm{L}$ and consisted of $5 \mu \mathrm{L}$ of TaqMan Genotyping Master Mix (Applied Biosystems), $0.25 \mu \mathrm{L}$ of a $40 \times$ primer probe assay mix (Applied Biosystems), $3.75 \mu \mathrm{L}$ of $\mathrm{H}_{2} \mathrm{O}$ and $1 \mu \mathrm{L}(10 \mathrm{ng})$ of genomic DNA. The amplification conditions consisted of $95^{\circ} \mathrm{C}$ for 10 minutes and 40 cycles of $95^{\circ} \mathrm{C}$ for 15 seconds and $60^{\circ} \mathrm{C}$ for 60 seconds followed by $50^{\circ} \mathrm{C}$ for two minutes. The data were analyzed using an automated software program (SDS 2.1; Applied Biosystems) to determine the genotype of each sample.

\section{Measurement of the plasma ghrelin levels in the $H$. pylori-negative $F D$ patients}

We measured the plasma ghrelin levels to evaluate their association with polymorphisms of GHRL in the H. pylorinegative FD patients and healthy volunteers. Blood samples were obtained after an overnight fast of $>12$ hours, immediately transferred to chilled polypropylene tubes containing $\mathrm{Na}_{2}$ EDTA and aprotinin, then centrifuged at $4^{\circ} \mathrm{C}$. One-tenth of the volume of $1 \mathrm{NHCl}$ was immediately added to the separated plasma. The acylated and des-acylated forms of ghrelin were measured using commercially available ELISA kits according to the manufacturer's instructions (Active Ghrelin ELISA Kit and Desacly-Ghrelin ELISA Kit, Mitsubishi Kagaku Iatron Inc., Tokyo, Japan). The intra- and inter-assay coefficients of variation (CV) were $6.5 \%$ and 9.8\% for acylated ghrelin and $3.7 \%$ and $8.1 \%$ for desacylated ghrelin, respectively.

\section{Statistical analysis}

For the statistical evaluation of group data, Students' $t$-test for paired data and an analysis of variance (ANOVA) for multiple comparisons were followed by Scheffe's F test. The Mann-Whitney $\mathrm{U}$ test was used for the analysis of categorical data. The distribution of alleles at each locus was assessed using the $\chi^{2}$ statistic of the Hardy-Weinberg equilibrium. To determine factors associated with disturbance of gastric emptying, a multiple logistic regression analysis was used at $95 \%$ confidence intervals and associated $p$ values. In addition, we evaluated the differences between two group factors (genotype of four SNPs of the GHRL gene, $H$. pylori-negative FD patients vs. healthy volunteers) for mean values of the acylated ghrelin levels using a two-way ANOVA analysis. The data analyses were performed using a standard software package (SPSS version 13.0, Chicago, IL). A p value of less than 0.05 was considered to be statistically significant.

\section{Power of the study}

In this study, we aimed to assess the potential association between the acylated ghrelin levels and symptoms of FD in patients with a preproghrelin 3056T- $>$ C allele status. In our study, we determined the sample size using the PS (Power and Sample size calculations program) software program, a gift from Vanderbilt University. The deviation of the acylated ghrelin levels in the healthy volunteers was approximately $3.2(\sigma=3.2)$. Using the above data, setting $\alpha=$ $0.05, \beta=0.80$, effect size $=0.625$ and the estimated mean ghrelin level in patients with $\mathrm{FD}=13.7 \mathrm{fmol} / \mathrm{mL}, 102$ healthy volunteers and 74 FD patients would be sufficient to identify clinically relevant differences. 
Table 3. Association between Acylated Ghrelin Levels and Genotypes of GHRL Gene in $\mathrm{H}$. pylori-negative FD Patients and Healthy Volunteers

\begin{tabular}{|c|c|c|c|c|c|c|c|c|}
\hline \multirow{3}{*}{ Genotypes } & \multicolumn{3}{|c|}{ H.pylori-negative FD patients } & \multicolumn{2}{|c|}{ Healthy volunteers } & \multirow{3}{*}{$\mathrm{p}^{1}$ value } & \multirow{2}{*}{\multicolumn{2}{|c|}{$\mathrm{p}^{2}$ value }} \\
\hline & Acylated & Des-acylated & $\mathrm{p}^{1}$ value & Acylated & Des-acylated & & & \\
\hline & $\begin{array}{c}\text { ghrelin } \\
\text { (fmol/min) }\end{array}$ & $\begin{array}{c}\text { ghrelin } \\
\text { (fmol/min) }\end{array}$ & & $\begin{array}{c}\text { ghrelin } \\
\text { (fmol/min) }\end{array}$ & $\begin{array}{c}\text { ghrelin } \\
\text { (fmol/min) }\end{array}$ & & $\begin{array}{l}\text { H.pylori-negative } \\
\text { FD vs HV }\end{array}$ & Genotyp \\
\hline Arg51Gln346CC & $11.97 \pm 1.48$ & $71.00 \pm 6.44$ & \multirow{2}{*}{$4 \begin{array}{cc}0.253 & 0.118 \\
(\mathrm{R}=0.198) & (\mathrm{R}=0.278)\end{array}$} & $14.94 \pm 1.59$ & $82.41 \pm 18.44$ & \multirow{2}{*}{$\begin{array}{cc}0.397 & 0.321 \\
(\mathrm{R}=0.121) & (\mathrm{R}=1.08)\end{array}$} & \multirow[t]{2}{*}{0.132} & \multirow[t]{2}{*}{0.259} \\
\hline $\mathrm{CT} / \mathrm{TT}$ & $12.78 \pm 0.79$ & $78.14 \pm 7.92$ & & $15.88 \pm 1.29$ & $94.76 \pm 14.51$ & & & \\
\hline Preproghrelin3056TT & $9.02 \pm 1.75$ & $62.29 \pm 6.64$ & \multirow{2}{*}{$\begin{array}{cc}0.048^{*} & 0.599 \\
(R=0.39) & (R=0.069)\end{array}$} & $14.93 . \pm 2.02$ & $89.22 \pm 18.09$ & \multirow{2}{*}{$\begin{array}{cc}0.236 & 0.138 \\
(\mathrm{R}=0.197) & (\mathrm{R}=0.245)\end{array}$} & \multirow[t]{2}{*}{$0.025^{* *}$} & \multirow[t]{2}{*}{0.521} \\
\hline $\mathrm{TC} / \mathrm{CC}$ & $13.87 \pm 1.51$ & $76.76 \pm 12.0$ & & $15.75 \pm 2.93$ & $97.37 \pm 21.40$ & & & \\
\hline Leu72Met408GG & $12.25 \pm 1.81$ & $75.51 \pm 7.05$ & \multirow{2}{*}{$\begin{array}{cc}0.889 & 0.594 \\
(\mathrm{R}=0.056) & (\mathrm{R}=0.067)\end{array}$} & $14.08 \pm 1.98$ & $88.35 \pm 16.02$ & \multirow{2}{*}{$\begin{array}{cc}0.534 & 0.109 \\
(\mathrm{R}=0.104) & (\mathrm{R}=0.264)\end{array}$} & \multirow[t]{2}{*}{0.347} & \multirow[t]{2}{*}{0.600} \\
\hline GT/TT & $11.37 \pm 2.67$ & $66.46 \pm 13.49$ & & $16.12 \pm 2.68$ & $98.56 \pm 25.55$ & & & \\
\hline Gln90Leu3412TT & $11.78 \pm 1.46$ & $70.69 \pm 6.31$ & \multirow{2}{*}{$\begin{array}{cc}0.441 & 0.332 \\
(\mathrm{R}=0.097) & (\mathrm{R}=0.115)\end{array}$} & $15.49 \pm 2.63$ & $101.00 \pm 25.73$ & \multirow{2}{*}{$\begin{array}{cc}0.324 & 0.723 \\
(\mathrm{R}=0.164) & (\mathrm{R}=0.059)\end{array}$} & \multirow[t]{2}{*}{0.099} & \multirow[t]{2}{*}{0.465} \\
\hline TA/AA & $12.23 \pm 1.01$ & $67.81 \pm 4.09$ & & $12.30 \pm 4.95$ & $112.15 \pm 38.05$ & & & \\
\hline
\end{tabular}

HV:healthy volunteers

* There was a significant relationship between preproghrelin 3056TT and acylated ghrelin levels in H.pylori-negative FD patients.

** In two-way ANOVA analysis, in preproghrelin 3056 genotype, there was a significant difference in acylated ghrelin levels between $H$.pylori-negative FD patients and healthy volunteers.

${ }^{1} \mathrm{P}$ value refer to the difference in each genotype for acylated ghrelin and des-acylated ghrelin levels by logistic regression analysis.

${ }^{2} \mathrm{P}$ value refer to the difference in two group factors(genotype; H.pylori-negative FD patients vs healthy volunteers) for mean values of acylated ghrelin levels by two-way ANOVA.

Table 4. Comparison of Tmax Value with Genotypes of GHRL Gene in H. pylori-negative FD Patients

\begin{tabular}{|c|c|c|c|}
\hline Genotypes & $\operatorname{Tmax}>60 \mathrm{~min}$ & $\operatorname{Tmax}<60 \mathrm{~min}$ & $\mathrm{p}$ value \\
\hline Arg51Gln346G->A CC & 31 & 42 & 0.249 \\
\hline $\mathrm{CT} / \mathrm{TT}$ & 1 & 0 & \\
\hline Preproghrelin $3056 \mathrm{~T}->\mathrm{C}$ TT & 16 & 26 & 0.624 \\
\hline $\mathrm{TC} / \mathrm{CC}$ & 14 & 18 & \\
\hline Leu72Met408C->A GG & 20 & 32 & 0.202 \\
\hline GT/TT & 12 & 10 & \\
\hline Gln90Leu3412T->A TT & 32 & 41 & 0.891 \\
\hline TA/AA & 0 & 1 & \\
\hline \multicolumn{4}{|c|}{ Comparison of Tmax value with genotypes of GHRL gene in healthy volunteer } \\
\hline Genotypes & $\operatorname{Tmax}>60 \min$ & $\operatorname{Tmax}<60 \mathrm{~min}$ & $\mathrm{p}$ value \\
\hline $\operatorname{Arg} 51 \mathrm{Gln} 346 \mathrm{G}->\mathrm{A} \quad \mathrm{CC}$ & 11 & 90 & 0.727 \\
\hline $\mathrm{CT} / \mathrm{TT}$ & 0 & 1 & \\
\hline Preproghrelin3056T- $>C \quad$ TT & 2 & 43 & 0.269 \\
\hline $\mathrm{TC} / \mathrm{CC}$ & 7 & 50 & \\
\hline Leu72Met $408 \mathrm{C}->\mathrm{A} \quad$ GG & 3 & 59 & 0.160 \\
\hline GT/TT & 5 & 35 & \\
\hline Gln90Leu3412T- $>$ A $\quad$ TT & 1 & 7 & 0.576 \\
\hline TA/AA & 9 & 85 & \\
\hline
\end{tabular}

significantly lower than those $(13.87 \pm 1.51 \mathrm{fmol} / \mathrm{mL})$ observed in the preproghrelin $3056 \mathrm{TC} / \mathrm{CC}$ genotype group. There was a significant relationship $(\mathrm{p}=0.048)$ between the preproghrelin 3056TT and acylated ghrelin levels in the $H$. pylori-negative FD patients (Table 3 ). In contrast, we could not find any significant correlations $(\mathrm{p}=0.253$; $\mathrm{p}=0.889$; $\mathrm{p}=$ $0.441)$ between the acylated ghrelin levels and the Arg51Gln (346G->A), Leu72Met (408C->A) or Gln90Leu (3412T->A) genotypes in the H. pylori-negative FD patients (Table 3 ). There were also no significant correlations between any of the four GHRL gene SNPs and the des-acylated ghrelin levels in the $H$. pylori-negative FD patients (Table 3). There were also no significant associations between any of the four GHRL gene SNPs and the acylated or des-acylated ghrelin levels in the healthy volunteers (Table 3). Moreover, we also determined whether the acylated ghrelin levels were different between the $H$. pylori-negative FD patients and the healthy volunteers for each genotype of the GHRL gene. According to a two-way ANOVA analysis of the preproghrelin $3056 \mathrm{~T}->\mathrm{C}$ genotype, there was a significant $(\mathrm{p}=0.025)$ difference in the acylated ghrelin levels between the $H$. pylori-negative FD patients and healthy volunteers.

\section{Comparison of the four GHRL gene SNPs with the Tmax value in the FD patients and healthy volun- teers}

Since low levels of serum acylated ghrelin were found to be linked to impaired gastric emptying in PDS patients in our previous study, we attempted to clarify whether any of the four GHRL gene SNPs were associated with the Tmax values in the H. pylori-negative FD patients and healthy volunteers. In the current study, we could not find any significant relationships $(\mathrm{p}=0.249 ; \mathrm{p}=0.624 ; \mathrm{p}=0.202 ; \mathrm{p}=0.891)$ between any of the four GHRL gene SNPs, including Arg51 Gln (346G->A), preproghrelin 3056T->C, Leu72Met (408C$>A$ ) and Gln90Leu (3412T->A), and the Tmax values in the H. pylori-negative FD patients (Table 4). In addition, there were no significant relationships $(\mathrm{p}=0.727 ; \mathrm{p}=0.269 ; \mathrm{p}=$ $0.160 ; \mathrm{p}=0.576$ ) between any of the four GHRL gene SNPs and the Tmax values in the healthy volunteers (Table 4).

\section{Comparison of the four GHRL gene SNPs with clini- cal parameters and symptoms in the $H$. pylori- negative FD patients}

Since the serum acylated ghrelin levels have been previously reported to be linked to BMI and eating disorders, we also investigated whether any of the four GHRL gene SNPs were associated with any of the clinical parameters or clini- 
Table 5. Comparison of Genotypes of GHRL Gene with Clinical Parameters in FD Patients

\begin{tabular}{|c|c|c|c|c|c|c|}
\hline \multirow[t]{2}{*}{ Variable } & \multicolumn{2}{|c|}{$\operatorname{Arg} 51 G \ln 346 \mathrm{G}->\mathrm{A}$} & \multirow[b]{2}{*}{$\mathrm{p}$ value } & \multicolumn{2}{|c|}{ Preproghrelin3056T- $>C$} & \multirow[b]{2}{*}{$\mathrm{p}$ value } \\
\hline & $\mathrm{CC}$ & $\mathrm{CT} / \mathrm{TT}$ & & TT & $\mathrm{TC} / \mathrm{CC}$ & \\
\hline Age & $59.2 \pm 14.4$ & 68 & 0.547 & $59.8 \pm 13.8$ & $54.4 \pm 14.9$ & 0.761 \\
\hline $\operatorname{Sex}(\mathrm{M} / \mathrm{F})$ & $36 / 37$ & $1 / 0$ & 0.294 & $19 / 18$ & $17 / 19$ & 0.599 \\
\hline $\operatorname{BMI}\left(\mathrm{kg} \cdot \mathrm{m}^{-2}\right)$ & $22.2 \pm 2.53$ & 20 & 0.388 & $22.6 \pm 2.45$ & $21.6 \pm 2.56$ & 0.096 \\
\hline SRQ-D & $9.87 \pm 0.72$ & 15 & 0.402 & $10.73 \pm 0.79$ & $9.16 \pm 1.05$ & 0.222 \\
\hline \multirow[t]{2}{*}{ Variable } & \multicolumn{2}{|c|}{ Leu72Met408C- $>$ A } & & \multicolumn{2}{|c|}{ Gln90Leu3412T- $>A$} & \\
\hline & GG & GT/TT & $\mathrm{p}$ value & TT & TA/AA & $\mathrm{p}$ value \\
\hline Age & $60.0 \pm 13.9$ & $57.7 \pm 15.5$ & 0.534 & $59.7 \pm 14.4$ & 62 & 0.084 \\
\hline $\operatorname{Sex}(M / F)$ & $22 / 20$ & $14 / 18$ & 0.294 & $36 / 37$ & $0 / 1$ & 0.599 \\
\hline $\operatorname{BMI}\left(\mathrm{kg} \cdot \mathrm{m}^{-2}\right)$ & $22.9 \pm 1.19$ & $20.1 \pm 1.01$ & $0.018^{*}$ & $22.2 \pm 2.53$ & 22.4 & 0.922 \\
\hline SRQ-D & $9.87 \pm 0.72$ & 15 & 0.402 & $9.76 \pm 0.69$ & 2 & 0.058 \\
\hline
\end{tabular}

cal symptoms, including the feeling of hunger, in the Japanese FD patients diagnosed according to the Rome III classification. There were no significant relationships between the preproghrelin 3056TT genotype and clinical parameters, such as age $(\mathrm{R}=0.036, \mathrm{p}=0.761)$, sex $(\mathrm{R}=0.062, \mathrm{p}=0.599)$, BMI ( $\mathrm{R}=0.195, \mathrm{p}=0.096)$ and the SRQ-D score $(\mathrm{R}=0.146$, $\mathrm{p}=0.222$ ) (Table 5). In addition, there were no significant relationships between either the GHRL Gln90Leu (3412T->A) genotype or the Arg51Gln346G->A genotype and the clinical parameters. In contrast, there was a significant relationship ( $\mathrm{R}=0.274, \mathrm{p}=0.018$ ) between the GHRL Leu72Met 408C->A genotype and BMI (Table 5). In the H. pylorinegative FD patients, the preproghrelin 3056TT genotype was significantly $(\mathrm{p}=0.047)$ associated with the feeling of hunger compared to the preproghrelin $3056 \mathrm{TC} / \mathrm{CC}$ genotype (Figure A). However, in the H. pylori-negative FD patients, there were no significant relationships between clinical symptoms and the Arg51Gln (346G- $>A$ ), Leu72Met (408C->A) or Gln90Leu (3412T->A) genotypes. In the $H$. pylori-negative PDS patients, the preproghrelin 3056TT genotype was significantly $(\mathrm{p}=0.045 ; \mathrm{p}=0.016)$ associated with the feeling of hunger and abdominal fullness after meals compared to the preproghrelin $3056 \mathrm{TC} / \mathrm{CC}$ genotypes (Figure B). There were no significant relationships between clinical symptoms and the genotypes of Arg51Gln (346G-> A), Leu72Met (408C->A) or Gln90Leu (3412T->A) in the H. pylori-negative PDS patients (Figure B).

\section{Discussion}

The major findings of this study are as follows: 1) there was a significant relationship between the preproghrelin 3056TT genotype and the serum levels of acylated ghrelin in the H. pylori-negative FD patients, 2) in the preproghrelin 3056T $>\mathrm{C}$ genotype group, there was a significant $(\mathrm{p}=0.025)$ difference in the acylated ghrelin levels between the $H$. pylori-negative FD patients and the healthy volunteers and 3) the preproghrelin 3056TT genotype was found to be significantly associated with the feeling of hunger in the $H$. pylori-negative FD patients.

Altered gut-brain interactions may underlie symptom generation in patients with FD. We herein reported that the acylated ghrelin levels are significantly lower in PDS patients than in healthy volunteers. In addition, there is a significant inverse relationship between the plasma acylated ghrelin levels and the Tmax values in PDS patients (3). Lee et al. reported that the total plasma ghrelin levels are significantly lower in dysmotility-like FD patients than in controls (20). Shinomiya et al. reported that the plasma acylated ghrelin and des-acylated ghrelin levels are not significantly different between FD patients and controls and that the plasma acylated ghrelin levels are correlated with subjective symptom scores in FD patients (21). Takamori et al. suggested that there are no significant associations among gastric emptying, the plasma ghrelin levels and psychological factors in FD patients (22). These results suggest that the relationship between the plasma ghrelin levels and FD symptoms remains uncertain. However, ghrelin may play an important role in the etiology of FD because it has wellestablished roles in increasing appetite and food intake and stimulating gastric emptying and acid secretion $(6,23)$. In our data, there were no significant differences in the distributions of the genotypes of the four GHRL gene SNPs between the $H$. pylori-negative FD patients and the healthy volunteers (Table 2).

Brain-gut interactions modulate appetite, feeding and digestion. The gut hormone blood levels are altered in patients with dyspeptic disorders, including those with FD, and may be involved in the regulation of appetite. Patients with dysmotility-like dyspepsia have higher serum concentrations of leptin, which are associated with gastritis and H. pylori infection (24). Tahara et al. reported that a CCK genotype is associated with PDS in Japanese men (25). In addition, we have also previously reported that there is a significant relationship between low levels of acylated ghrelin linked to appetite and the Tmax values (3). Stanghellini et al. reported that disturbed gastric emptying is associated with satiation and impaired food intake (26). Therefore, it is critical to clarify whether the genotypes of ghrelin affect the Tmax values in FD patients and healthy volunteers. In our study, there were no significant relationships between the Tmax values as a marker of gastric motility and any of the four GHRL gene SNPs, including Arg51Gln (346G->A), preproghrelin 3056T- $>$ C, Leu72Met (408C- $>$ A) and Gln90Leu (3412T->A) in the FD patients and healthy volunteers. Gastric motility is affected by various gut hormones, including motilin, ghrelin, cholecystokinin, GLP-1 and peptide YY (27). It is of clinical importance to consider the relationship between gastric acidity and gastric motility because Lee et al. and Schwartz et al. both reported that intraduodenally administered acid affects gastroduodenal motility as well as visceral hypersensitivity $(28,29)$. Furthermore, Saito et al. reported that acceleration of gastric emptying was observed in an $H$. pylori-infected animal model (30). In contrast, in our previous study, $H$. pylori infection reduced the number 


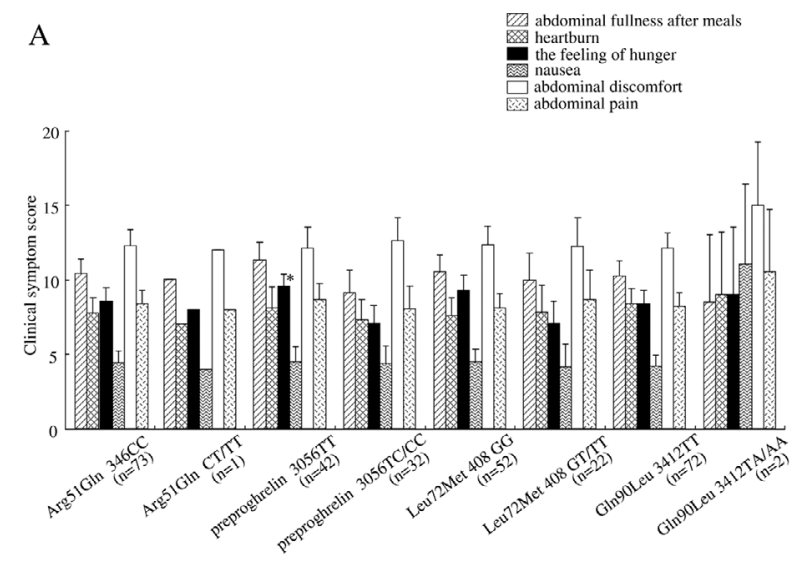

B

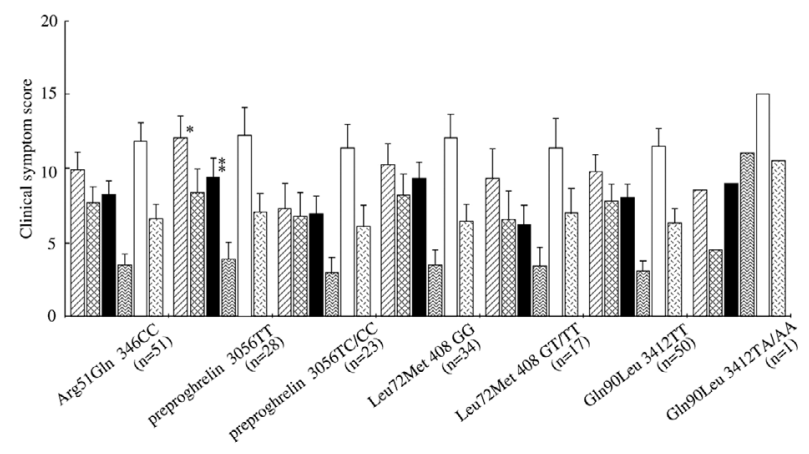

Figure. Associations between the four preproghrelin genotypes and clinical symptoms in the $H$. pylori-negative FD and PDS patients. A: There were no significant relationships between Arg51GIn (346G->A), Leu72Met (408C->A), GIn90Leu (3412T->A) and various clinical symptoms. Among the Japanese subjects, the preproghrelin3056TT genotype was significantly ( $p=0.0485)$ associated with the feeling of hunger in the $H$. pylori-negative FD patients compared to the preproghrelin 3056TC and CC genotypes. Arg51GIn 346CC (n=73), Arg 51GIn 346CT/TT (n=1); Leu72Met 408GG (n=52), Leu72Met 408GT/TT (n=22); Gln90Leu 3412TT $(n=72)$, Gln90Leu 3412TA/AA $(n=2)$; preproghrelin 3056TT $(n=42)$, preproghrelin 3056 TC/CC $(n=32) * v s$. preproghrelin 3056 TC/CC genotypes. B: There were no significant relationships between Arg 51GIn (346G->A), Leu72Met (408C->A), Gln90Leu (3412T$>A)$ and various clinical symptoms. In the Japanese $H$. pylorinegative PDS patients, the preproghrelin 3056 TT genotype was significantly $(p=0.045 ; p=0.016)$ associated with the feeling of hunger and abdominal fullness compared to the preproghrelin 3056 TC and CC genotypes. Arg51Gln 346CC $(n=51)$; Leu72Met 408GG $(n=34)$, Leu72Met 408GT/TT $(n=17)$; Gln90Leu 3412TT $(n=50)$, Gln90Leu 3412TA/AA $(\mathrm{n}=1)$; preproghrelin 3056TT $(\mathrm{n}=28)$, preproghrelin 3056TC/ CC $(\mathbf{n}=23) * v s$. preproghrelin $3056 \mathrm{TC} / \mathrm{CC}$ genotypes. **vs. preproghrelin $3056 \mathrm{TC} / \mathrm{CC}$ genotypes.

of ghrelin-producing cells that are linked to gastric emptying (31). Suzuki et al. reported that the plasma ghrelin levels correlate well with the serum levels of the pepsinogen I/II (PGI/II) ratio (32) and are decreased in association with advancing gastric mucosal atrophy. Taking together the find- ings of previous reports and our data, the serum ghrelin levels may be affected by $H$. pylori infection (30-32). In our data, there was a significant relationship between preproghrelin 3056T->C genotype and the acylated ghrelin levels in the $H$. pylori-negative FD patients. Therefore, in future studies, we should investigate why the preproghrelin 3056T->C genotype could not be linked to the Tmax value as a marker of gastric emptying in the $H$. pylori-negative subjects. In addition, due to the small number of subjects in the Rome III subgroup, type II errors cannot be excluded. Therefore, our results should be treated with caution until they are replicated in different populations and other races.

There is increasing evidence that susceptibility to functional gastrointestinal disorders (FGIDs) is also influenced by hereditary factors (33-35). Holtmann et al. reported that homozygous GN $\beta 3$ 825CC is associated with upper abdominal symptoms unrelated to meals in patients in Germany (36). We also first reported that the GN $33 \mathrm{CC}$ variant is significantly associated with disturbance of gastric emptying in PDS patients without gastroesophageal reflux symptoms (37). In this study, since the serum ghrelin level has been reported to be associated with food intake and gastric motility, we focused on the relationships between the genotypes of the GHRL gene SNPs and the feeling of hunger in FD patients. The preproghrelin 3056T- $>C$ genotype was found to be significantly associated $(\mathrm{p}=0.045)$ with the feeling of hunger and abdominal fullness in the $H$. pylorinegative PDS patients. Miwa et al. reported that FD patients eat meals irregularly and do not have an appetite (38). The authors speculated that eating habits associated with the feeling of hunger are related to the pathophysiology of FD, especially PDS (38). Therefore, we also speculate that the feeling of hunger linked to appetite is a very important factor in considering the etiology of FD in certain patients with GHRL gene SNPs, such as preproghrelin 3056T->C. In contrast, in this study, there were no significant relationships between the three other GHRL gene SNPs (Arg51Gln (346G->A), Leu72Met (408C->A) and Gln90Leu (3412T-> A)) and the feeling of hunger in the H. pylori-negative PDS patients. Considering that ghrelin infusion also increases food intake and the sensation of hunger compared with saline infusion alone (7), measuring the genotypes of the GHRL gene may significantly reflect the activity of serum ghrelin compared to that of ghrelin. Ukkola et al. reported that Arg51GlnSNP is associated with lower ghrelin levels (10). However, in our data, the $\operatorname{Arg} 51 \mathrm{Gln}(346 \mathrm{G}->\mathrm{A})$ genotype was almost entirely of the $\mathrm{CC}$ type in both the Japanese FD patients and healthy volunteers. Ando et al. reported that the preproghrelin gene 3056T->C SNP is associated with changes in the basal ghrelin concentrations (39). It is controversial whether any of the ghrelin gene SNPs alter the levels of ghrelin and/or obestatin $(40,41)$. In this study, we also confirmed that the preproghrelin 3056TT genotype is significantly linked to low levels of acylated ghrelin in $H$. pylori-negative FD patients compared to healthy volunteers. The active form of ghrelin is acylated ghrelin, the serin3 
residue of which is posttranslationally octanoylated. Recently, the enzyme that octanoylates the serine 3 residue of ghrelin has been discovered to be ghrelin $O$-acyltransferase (GOAT) (42). Considering that there were no significant differences in the distributions of the genotypes of the four GHRL gene SNPs between the H. pylori-negative FD patients and healthy volunteers, we speculate that the acylated ghrelin levels in healthy volunteers expressing the preproghrelin 3056 TT genotype may be modified by other factors, such as upregulation of the activity of GOAT. In addition, the Met 72 allele has been shown to be associated with an earlier age of self-reported onset of obesity in several studies $(9,11)$ and with higher BMI values. However, a recent Danish study concluded that the Leu 72 Met polymorphism of the ghrelin gene is not associated with metabolic syndrome or related quantitative traits (43). The Gln90Leu SNP has also been linked to obesity (44). In our data, there were no significant relationships $(\mathrm{p}=0.21 ; \mathrm{p}=0.94)$ between BMI and the genotypes of Arg51Gln (346G->A) or Gln90 Leu $(3412 \mathrm{~T}->\mathrm{A})$ in the $H$. pylori-negative FD patients. In contrast, the genotype of Leu72Met (408C->A) was found to be significantly $(\mathrm{p}=0.018)$ associated with $\mathrm{BMI}$ in the $H$. pylori-negative FD patients. Further studies are needed to investigate the precise mechanisms through which the genotypes of preproghrelin are linked to dysfunction of acylated ghrelin and whether the preproghrelin 3056T->C genotype contributes to the long-term regulation of appetite and BMI (6).

Akamizu et al. reported the ability of repeated ghrelin administration to increase appetite and food intake in patients with FD (45). Recently, the acyltransferase responsible for ghrelin acylation, GOAT, was discovered (42). The posttranslational modification of octanoylation appears to be essential for GH-releasing ability (46) as well as acylated ghrelin's regulation of food intake and insulin secretion (47). Considering the present results and those of a previous study, ghrelin administration may be more useful for therapy in certain FD patients expressing the preproghrelin 3056TT genotype. The relationship between the ghrelin signaling system and eating behavior makes identifies ghrelin, growth hormone secretagogue receptor (GHSR) and GOAT as good candidate genes for hunger sensation and the risk of eating disorders $(45,48)$.

Taken together, in this study, the preproghrelin 3056TT genotype is significantly associated with reductions in the levels of acylated ghrelin and the feeling of hunger in $H$. pylori-negative FD patients. Further studies are needed to clarify the mechanisms through which the preproghrelin 3056TT genotype is associated with reduction of the acylated ghrelin levels and the feeling of hunger in $H$. pylori-negative FD patients.

The authors state that they have no Conflict of Interest (COI).

\section{References}

1. Tack J, Talley NJ, Camilleri M, et al. Functional gastroduodenal disorders. Gastroenterology 130: 1466-1479, 2006.

2. Quigley EM. Gastric emptying in functional gastrointestinal disorders. Aliment Pharmacol Ther 20 (Suppl 7): 56-60, 2004.

3. Shindo T, Futagami S, Hiratsuka T, et al. Comparison of gastric emptying and plasma ghrelin levels in patients with functional dyspepsia and non-erosive reflux disease. Digestion 79: 65-72, 2009.

4. Fischer H, Heidemann T, Hengst K, Domschke W, Konturek JW. Disturbed gastric motility and pancreatic hormone release in diabetes mellitus. J Physiol Pharmacol 49: 529-541, 1998.

5. Shiiya T, Nakazato M, Mizuta M, et al. Plasma ghrelin levels in lean and obese humans and the effect of glucose on ghrelin secretion. J Clin Endocrinol Metab 87: 240-244, 2002.

6. Cummings DE. Ghrelin and the short-and long-term regulation of appetite and body weight. Physiol Behav 89: 71-84, 2006.

7. Quigley EM. Gastric motor and sensory function, and motor disorders of the stomach. In: Gastrointestinal and Liver Disease, Pathophysiology/Diagnosis/Management. Feldman M, Friedman LS, Sleisenger MH, Eds. WB Saunders, Phiadelphia, 2002: 691714.

8. Talley NJ, Stanghellini V, Heading RC, Koch KL, Malagelada JR, Tytgat GN. Functional gastroduodenal disorders. Gut 45 (Suppl 2): II37-II42, 1999.

9. Ukkola O, Ravussin E, Jacobson P, et al. Mutations in the preproghrelin/ghrelin gene associated with obesity in humans. J Clin Endocrinol Metab 86: 3996-3999, 2001.

10. Ukkola $\mathrm{O}$, Ravussin E, Jacobson $\mathrm{P}$, et al. Role of ghrelin polymorphisms in obesity based on the three different studies. Obes Res 10: 782-791, 2002.

11. Korbonits M, Gueorguiev M, O'Grady E, et al. Avariation in the ghrelin gene increases weight and decreases insulin secretion in tall, obese chiidlen. J Clin Endocrinol Metab 87: 4005-4008, 2002.

12. Drossman DA. The functional gastrointestinal disorders and the Rome III process. Gastroenterology 130: 1377-1390, 2006.

13. McColl K, Murray L, El-Omar E, et al. Symptomatic benefit from eradicating Helicobacter pylori infection in patients with nonulcer dyspepsia. N Engl J Med 339: 1869-1874, 1998.

14. Portincasa P, Altomare DF, Moschetta A, et al. The effect of acute oral erythromycin on gallbladder motility and on upper gastrointestinal symptoms in gastrectomized patients with and without gallstones: a randomized, placebo-controlled ultrasonographic study. Am J Gastroenterol 95: 3444-3451, 2000.

15. El-Omar EM, Banerjee S, Wirz A, McColl KE. The Glasgow dyspepsia severity score-a tool for the global measurement of dyspepsia. Eur J Gastroenterol Hepatol 8: 967-971, 1996.

16. Rockliff BW. A brief self-rating questionnaire for depression (SRQ-D). Psychosomatics 10: 236-243, 1969.

17. Fukuhara S, Suzukamo Y. Instruments for measuring Healthrelated Quality of Life-SF8 and SF36. J Clin Exp Med [Igaku no Ayumi] 213: 133-136, 2005 (in Japanese).

18. Hellmig S, Von Schoning F, Gadow C, et al. Gastric emptying time of fluids and solids in healthy subjects determined by $13 \mathrm{C}$ breath tests: influence of age, sex and body mass index. J Gastroenterol Hepatol 21: 1832-1838, 2006.

19. Futagami S, Shindo T, Kawagoe T, et al. Migration of eosinophils and CCR2-/CD68-double positive cells into the duodenal mucosa of patients with postinfectious functional dyspepsia. Am J Gastroenterol 105: 1835-1842, 2010.

20. Lee KJ, Cha DY, Cheon SJ, Yeo M, Cho SW. Plasma ghrelin levels and their relationship with gastric emptying in patients with dysmotility-like functional dyspepsia. Digestion 80: 58-63, 2009.

21. Shinomiya T, Fukunaga M, Akamizu $T$, et al. Plasma acylated 
ghrelin levels correlate with subjective symptoms of functional dyspepsia in female patients. Scand J Gastroenterol 40: 648-653, 2005.

22. Takamori K, Mizuta Y, Takeshima F, et al. Relation among plasma ghrelin level, gastric emptying, and psychologic condition in patients with functional dyspepsia. J Clin Gastroenterol 41: 477-483, 2007.

23. Wren AM, Bloom SR. Gut hormones and appetite control. Gastroenterology 132: 2116-2130, 2007.

24. Lankarani KB, Moghadami M, Masoumpoor M, Geramizadeh B, Omrani GR. Serum leptin level in patients with functional dyspepsia. Dig Liver Dis 36: 717-721, 2004.

25. Tahara T, Arisawa T, Shibata T, et al. 779TC of CCK-1 intron 1 is associated with postprandial syndrome (PDS) in Japanese male subjects. Hepatogastroenterology 56: 1245-1248, 2009.

26. Stanghellini V, Tosetti C, Paternico A, et al. Risk indicators of delayed gastric emptying of solids in patients with functional dyspepsia. Gastroenterology 110: 1036-1042, 1996.

27. Khoo J, Rayner CK, Feinle-Bisset C, Jones KL, Horowitz M. Gastrointestinal hormonal dysfunction in gastroparesis and functional dyspepsia. Neurogastroenterol Motil 22: 1270-1278, 2010.

28. Lee KJ, Vos R, Janssens J, Tack J. Influence of duodenal acidification on the sensorimotor function of the proximal stomach in humans. Am J Physiol Gastrointest Liver Physiol 286: G278G284, 2004.

29. Schwartz MP, Samsom M, Smout AJ. Chemospecific alterations in duodenal perception and motor response in functional dyspepsia. Am J Gastroenterol 96: 2596-2602, 2001.

30. Saito Y, Suzuki H, Tsugawa H, et al. Dysfunctional gastric emptying with down-regulation of muscle-specific microRNAs in Helicobacter pylori-infected mice. Gastroenterology 140: 189-198, 2011.

31. Tatsuguchi A, Miyake K, Gudis K, et al. Effect of Helicobacter pylori infection on ghrelin expression in human gastric mucosa. Am J Gastroenterol 99: 2121-2127, 2004.

32. Suzuki H, Masaoka T, Hosoda H, et al. Plasma ghrelin concentration correlates with the levels of serum pepsinogen I and pepsinogen I/II ratio-a possible novel and non-invasive marker for gastric atrophy. Hepatogastroenterology 51: 1249-1254, 2004.

33. Morris-Yates A, Talley NJ, Boyce PM, Nandurkar S, Andrews G. Evidence of a genetic contribution to functional bowel disorder. Am J Gastroenterol 93: 1311-1317, 1998.

34. Levy RL, Jones KR, Whitehead WE, Feld SI, Talley NJ, Corey LA. Irritable bowel syndrome in twins; heredity and social learning both contribute to etiology. Gastroenterology 121: 799-804, 2001.
35. Kalantar JS, Locke GR 3rd, Zinsmeister AR, Beighley CM, Talley NJ. Familial aggregation of irritable bowel syndrome: a prospective study. Gut 52: 1703-1707, 2003.

36. Holtmann G, Siffert W, Haag S, et al. G-protein $\beta 3$ subunit 825 $\mathrm{CC}$ genotype is associated with unexplained (functional) dyspepsia. Gastroenterology 126: 971-979, 2004.

37. Shimpuku M, Futagami S, Kawagoe T, et al. G-protein $\beta 3$ subunit 825CC genotype is associated with postprandial distress syndrome with impaired gastric emptying and with the feeling of hunger in Japanese. Neurogastroenterol Motil 23: 1073-1080, 2011.

38. Miwa H. Life style in persons with functional gastrointestinal disorders: large-scale internet survey of lifestyle in Japan. Neurogastroenterol Motil 24: 464-471, e217, 2012.

39. Ando T, Ichimaru Y, Konjiki F, Shoji M, Komaki G. Variations in the preproghrelin gene correlate with higher body mass index, fat mass, and body dissatisfaction in young Japanese women. Am J Clin Nutr 86: 25-32, 2007.

40. Ogiso K, Asakawa A, Amitani H, Inui A. Ghrelin: a gut hormonal basis of motility regulation and functional dyspepsia. J Gastroenterol Heaptol 26 (Suppl 3): 67-72, 2011.

41. Zou CC, Huang K, Liang L, Zhao ZY. Polymorphisms of the ghrelin/obestatin gene and ghrelin levels in Chinese children with short stature. Clin Endocrinol 69: 99-104, 2008.

42. Yang J, Brown M, Liang G, et al. Identification of the acyltransferase that octanoylates ghrelin, an appetite-stimulating peptide hormone. Cell 132: 387-396, 2008.

43. Bing C, Ambye L, Fenger M, et al. Large-scale studies of the Leu 72Met polymorphism of the ghrelin gene in relation to the metabolic syndrome and associated quantitative traits. Diabet Med 22: 1157-1160, 2005.

44. Hinney A, Hoch A, Geller F, et al. Ghrelin gene: identification of missense variants and a frameshift mutation in extremely obese children and adolescents and healthy normal weight students. J Clin Endocrinol Metab 87: 2716-2719, 2002.

45. Akamizu T, Iwakura H, Ariyasu $\mathrm{H}$, et al. Repeated administration of ghrelin to patients with functional dyspepsia: its effects on food intake and appetite. Eur J Endocrinol 158: 491-498, 2008.

46. Kojima M, Hosoda H, Date Y, Nakazato M, Matsuo H, Kangawa $\mathrm{K}$. Ghrelin is a growth-hormone-releasing acylated peptide from stomach. Nature 402: 656-660, 1999.

47. Gutierrez JA, Solenberg PJ, Perkins DR, et al. Ghrelin octanoylation mediated by an orphan lipid transferase. Proc Natl Acad Sci USA 105: 6320-6325, 2008.

48. Liu B, Garcia EA, Korbonits M. Genetic studies on the ghrelin, growth hormone secretagogue receptor (GHSR) and ghrelin Oacyl transferase (GOAT) genes. Peptides 32: 2191-2207, 2011.

(C) 2013 The Japanese Society of Internal Medicine http://www.naika.or.jp/imonline/index.html 